\title{
Ceremonial y loables costumbres de la Catedral de Cuenca durante la Semana Santa en el año 1617
}

\section{Ceremonial and coomendable customs of the Cathedral of Cuenca during the Holy Week in the year 1617}

\author{
Eulogio Fernández Carrasco ${ }^{1}$ \\ Universidad Nacional de Educación a Distancia. UNED. España. \\ cuencajucar@gmail.com

\section{Resumen:}

La Semana Santa, ha sido uno de los raros casos de la literatura religiosa en la que pueda dar cabida a un posible procedimiento privilegiado que posibilita el uso de las normas reguladoras de los Ceremoniales eclesiásticos. Este trabajo pone en antecedentes, la importancia de este instrumento normativo, como son los Ceremoniales, para la consecución de los fines ejercitados por el organismo encargado de conseguir tales objetivos, y que no son otros que normativizar los actos religiosos que acontecen en dos de los días más señalados en España, cuales son el Jueves y el Viernes Santo. En relación a la localización del material de nuestro objeto de estudio, hay que hacer notar, que dentro de los trabajos que versan sobre los Ceremoniales eclesiásticos del siglo XVII, no consta en la actualidad una monografía, sino sólo referencias, que aborden el examen que se hace aquí. Para el estudio de este trabajo, hemos estudiado en los manuscritos existentes en la Biblioteca Nacional.

Palabras clave: Semana Santa, Ceremonial, Monumento, Sacramento, Evangelio.

Abstract: The Holy Week, it has been one of the rare cases of the religious literature in the one that could give content to a possible privileged procedure that makes possible the use of the regulatory procedure of the Ceremonial ecclesiastics. This work puts in precedents, the importance of this normative instrument, since they are the Ceremonial ones, for the attainment of the ends exercise for the organism entrusted to obtain such aims, and your that are not others that regulate the religious acts that happen in two of the days most indicated in Spain, which are the Thursday and the Good Friday. In relation to the location of

\footnotetext{
1 Profesor Contratado Doctor de Historia del Derecho y de las Instituciones. Investigador en el Máster Universitario en Protocolo de la Uned. Miembro del Grupo de Investigación: Historia del Pensamiento JurídicoPolítico en la Uned. Miembro del Instituto de Historia de la Intolerancia dentro de la Academia de Jurisprudencia y Legislación. Miembro colaborador de la revista Anuario de Historia del Derecho Español.
} 
the material of our object of study, it is necessary to make notice, that inside the works that turn on the Ceremonial ecclesiastics of the 17th century, a monograph does not consist at present, but only you index, that approach the examination that is done here. For the study of this work, we have studied in the existing manuscripts in the National Library.

Key Words: Holy, Ceremonial week, monument, Sacramento, Gospel.

\section{Sumario.}

1. Introducción.

2. Documentación.

3. El Jueves Santo en la regulación del ceremonial de 1617.

4. El Viernes Santo en la regulación del ceremonial de 1617.

5. El Sábado Santo en la regulación del ceremonial de 1617.

6. Conclusiones.

7. Bibliografía.

\section{Summary.}

1. Introduction.

2. Documentation.

3. The Holy Thursday in the regulation of the ceremonial of 1617.

4. The Good Friday in the regulation of the ceremonial of 1617.

5. The Holy Saturday in the regulation of the ceremonial of 1617.

6. Conclusions.

7. Bibliography.

\section{INTRODUCCIÓN.}

La Semana Santa comenzaba con la procesión del Domingo de Ramos y su correspondiente Misa solemne. Durante la procesión, los asistentes portaban ramos y palmas previamente bendecidos.

Al llegar el Miércoles Santo y días sucesivos se interpretaban los oficios de Maitines que se dicen en los tres últimos días de la Semana Santa.

En el día de Jueves Santo, se comienza el Triduo Pascual, en donde se celebran tres importantes ceremonias, una es la Misa vespertina, otra es el lavatorio y por último, la visita al Monumento. En este día se lleva a cabo la consagración de dos hostias, la una que es la que consume el celebrante y la otra que se conserva para el día siguiente. Para lograrlo, se 
disponían o componían Altares y estrados y grandes cantidades de incienso. El lavatorio de pies, es una ceremonia de gran simbolismo en donde se eligen a personas pobres para Ilevarlo a cabo. El Monumento, o lo que es lo mismo el Altar o aparato que se forma en las iglesias el día del Jueves Santo, donde se coloca un arca a modo de sepulcro y en donde se pone en ella la segunda hostia consagrada ese mismo día de Jueves para ser consumida en los oficios del Viernes Santo. En el Monumento, se llevan a cabo, lo que se denomina recorrer las estaciones para hacer presente la devoción cristiana al hacer oración delante del Santísimo Sacramento en los días de Jueves y Viernes Santo.

El Viernes Santo se lleva a cabo la adoración de la cruz, momento en el que se procede al ofrecimiento de ofrendas. Ese día se entregaban limosnas en oro o plata o dinero para los Monumentos de las iglesias, como por ejemplo, las cruces, o incluso dinero para repartir a los pobres. Otra posibilidad era la de entregar tejidos como raso o tafetán para cubrir las cruces. También la cruz de la capilla ese día era tapada con un paño de tafetán, raso o ceutí negro y algunas familias nobles, usaban prendas negras o de luto. Cabe destacar por su importancia desde el punto de vista político religioso la concesión de perdones por parte del poder real, que se llevaba a cabo el Viernes Santo, convirtiéndose la misericordia y posterior perdón en un acto religioso, debido al carácter marcadamente religioso de ese día en donde se producía tal perdón.

El Sábado Santo se caracteriza por la continuación de los actos y ceremonias religiosas, concretamente en el ámbito de la polifonía.

Se termina la Semana Santa con el día más esplendoroso, que es la Pascua de Resurrección, debido al carácter festivo reinante, produciéndose la Procesión después de la Misa, donde se culmina el encuentro ente Cristo y su Madre y donde los participantes se manifiestan con alegría y aplausos en dicho acontecimiento.

El siglo en que discurre este trabajo, es decir, el siglo XVII, se considera como el origen de la tradición de festejar la Semana Santa y es cuando se fundan las primeras cofradías conquenses para llevar a cabo los actos que sirven para aclamar y para conmemorar la muerte de Cristo plasmándolo en sus famosas procesiones. 


\section{DOCUMENTACIÓN.}

El actual artículo, gira sobre la documentación existente en la Biblioteca Nacional, específicamente con la signatura siguiente:

BN. 3/55956. Libro de Ceremonias y loables costumbres, que la Santa Iglesia de Cuenca ha guardado, y guarda en el Culto, y Oficio Divino, con sus Prelados dentro del contenido de la Concordia In Dei Nomine Amén. Fechado el 24 de octubre de 1617.

En él, están recopiladas las vicisitudes y andaduras de estas reglas. Esta documentación, cierra prácticamente la información existente en el citado Archivo. Son obras que recogen la labor de diferentes Obispos conquenses, notables por su labor al frente de la Catedral de Cuenca, destacando a Pacheco, Obispo de Cuenca y del Consejo del Rey. Son Ceremoniales y loables costumbres de la Santa Iglesia Catedral de Cuenca que ha de hacerse conforme a lo determinado por la Sagrada Congregación y todo ello, con arreglo a las del Ceremonial Romano. Por ello los Obispos, quieren que se apliquen en Cuenca con las modificaciones propias de la época que vive la Iglesia.

Se reúnen en Cuenca, el día 24 de octubre de 1617, dentro del pontificado de Pablo $V$ y en presencia del Notario Apostólico Florián de Valenzuela y de testigos, de una parte Andrés Pacheco, Obispo de Cuenca y del Consejo Real que actuaba en nombre de los obispos que le sucedieron, y de otra el Deán y el Cabildo de la Catedral de Cuenca. Estando todos en su Cabildo según el uso y costumbre que había de juntarse para las cosas que le correspondían y estando presentes: don Juan Bautista de Espinosa, Deán, don Alonso Téllez Girón, Arcediano de Huete; don Cristóbal de Ibarra y Mendoza, Arcediano de Moya; don Alonso Cuello de Rivera, Arcediano de Alarcón; don Jerónimo Deva, Abad de la Sey; don Rodrigo Zapata; don Diego Marzo, arcipreste; don Francisco de Mendoza; doctor Martín Yañez de Padilla; don Diego Castillo Valera; don Alonso del Pozo Palomino; doctor de Valenzuela Velázquez; Manuel de Ledesma; doctor don Juan de Pereda y Gudiel; Pedro Muñoz de Ortega, todos canónigos de la Iglesia Catedral de Cuenca, por ellos mismos y los que fueren presentes allí o en adelante, a continuación, prestaron voz y caución suficiente para estar y 
pasar por lo que a ellos tocase o al dicho Cabildo en cuanto a pagos y rentas que para ello se obligaron en la dicha caución. El Obispo y el dicho Cabildo expusieron, que por cuanto entre el obispo y el Deán, existían pleitos pendientes ante el Papa y otros tribunales sobre la forma de actuar y proceder en las causas criminales de Dignidades y Canónigos, opinando además el obispo, que en los autos se debía de hablar en plural, y no por la fórmula de Provisor en singular.

Por ello, el Deán y el Cabildo, pretendían que los dichos adjuntos habían de hablar y actuar juntamente con los Obispos o sus Provisores como jueces que eran y habían sido de las dichas causas, proveyendo, mandando y juzgando en ellas como tales jueces, hablando en plural con los dichos señores Obispos, sus Provisores y jueces adjuntos en toda las peticiones y demás autos, que en las dichas causas, se proveyesen como era costumbre usada y guardada.

La razón que se argumenta, era de que en esos momentos, existía un pleito pendiente en la Sagrada Congregación de Ritos sobre y en razón de las ceremonias que se habían de guardar y observar en la Iglesia, y en la que dicha Congregación decretó y mando que se guardasen las del Ceremonial Romano. Por ello, el Obispo de Cuenca y su Cabildo, querían guardar y poner en ejecución, como hijos de obediencia de la Santa Sede Apostólica y por ser el sitio y planta de la dicha Santa Iglesia, siendo diferente del que se requería tener para el uso y observancia de algunas de las ceremonias del dicho Ceremonial. Se argumenta por otro lado, que habían sido otras las que se habían usado en la dicha Santa Iglesia, conforme a las usadas y guardadas en las Iglesias Catedrales de los reinos de Castilla y loables costumbres con arreglo a lo dispuesto por los Sagrados Cánones.

Por ello, pretendían que se usaran y guardasen de ahí en adelante, para siempre jamás, así por los Obispos como por el dicho Deán y Cabildo, ceremonias que en ese instrumento irían declaradas, y que debido a la dificultad que existía de usar y guardar otras y por ser como eran loables, y dado que se habían usado desde tiempo inmemorial a esa parte en la dicha Catedral, con las que de nuevo se habían añadido y se iban introduciendo y que por otro lado, eran conformes al Ceremonial Romano y demás costumbres de las iglesias en España. 
Por tanto el Obispo y el Cabildo acordaron, que en el conocimiento de las causas criminales contra Dignidades y Canónigos, se guardase la costumbre, de que el dicho Deán, Cabildo y sus jueces adjuntos, habían de actuar en conjunto con los Obispos o sus Provisores, hablando las peticiones con todos, mandando, juzgando y proveyendo cualquier auto y no los unos sin los otros, conforme al Santo Concilio de Trento. Para ello, propusieron que se hiciera de la manera siguiente: Nos (nombre) Obispo, o Provisor y (nombre). (nombre). Jueces adjuntos, mandamos y proveemos. $Y$ ante Nos (nombre) el Obispo, o Provisor, (nombre) (nombre) Jueces adjuntos, se presentaron las peticiones y pedimentos 0 instrumentos siguientes. Y firmando todos, como en las dichas causas se habían hecho siempre en que se le llamara jueces, como lo era cualquier petición y auto que se proveyese, según tenían y habían usado con arreglo a la costumbre y continua posesión de llamarles tales jueces y proveer juntamente los dichos autos cuando procediesen juntos Obispo, o Provisor y jueces adjuntos conforme al dicho Santo Concilio.

En cuanto a las ceremonias en que el Obispo por sí y su Dignidad Episcopal y el dicho Cabildo estaban conformes, se acordó que se hiciesen en la dicha Santa Iglesia Catedral, bajo el beneplácito del Papa para cuidar los inconvenientes que se habían declarado. Por tanto, convinieron que se debía de hacer y guardar el Libro de Ceremonias y loables costumbres que la Santa Iglesia de Cuenca había guardado y guardaba en el culto y oficio divino con sus Prelados.

\section{EL JUEVES SANTO EN LA REGULACIÓN DEL CEREMONIAL DE 1617.}

La regulación de estas ceremonias, está recogida en el libro de Ceremonias y loables costumbres, que la Santa Iglesia de Cuenca ha guardado, y guarda en el Culto, y Oficio Divino, con sus Prelados de fecha 24 de octubre de 1617. Y expone lo siguiente:

El oficio del Jueves Santo².

\footnotetext{
${ }^{2}$ Capítulo dieciocho. Del oficio del Jueves Santo.
} 
A la hora acordada iba todo el Cabildo a recoger al Obispo. En el caso de que hubiera que celebrar, y acompañado de esta manera, se vestía en el Sagrario, donde el recado de Misa Pontifical estaba colocado, a todo ello, le asistían los Ministros. Para la bendición de los Óleos, se vestían de Presbíteros, Dignidades, Canónigos, Racioneros enteros, para Diáconos y Subdiáconos Racioneros enteros y medios, y suplían los capellanes si faltaban Ministros. Acabada la Nona, iba el Obispo, acompañado con los dichos Ministros, al Altar mayor y en la última grada de él comenzaba la Misa y la proseguía como las demás Misas de Pontifical, hasta que se pronunciaban las palabras: Per quem haec omnia Domine exclusive, que bendecían los Óleos, diciendo las oraciones y guardando en lo demás lo que el Pontifical disponía. Le acompañaban los doce Presbíteros, siete Diáconos y siete Subdiáconos, que tenían sus asientos entre los dos coros, a los lados de la mesa en que se hacía la bendición.

Acabada la Misa, como disponía el Misal, se quitaba el Obispo la Casulla, Manipulo, Túnica y Tunicela y tomaba capa pluvial blanca en su silla, después, llevaba el Santísimo Sacramento al Monumento, portando las varas del Palio, los Presbíteros revestidos y los demás con velas encendidas.

Salía la procesión por la puerta de la capilla mayor e iba por la de los Caballeros, bajaba hasta las puertas de la iglesia y volvía a la nave donde estaba el Monumento. Acto seguido, subía el Obispo con sus Ministros al Altar y por encima de él, el Cáliz con el Santísimo Sacramento, haciendo entonces genuflexión y levantándose a por incienso en el incensario. Después de haberle incensado tres veces de rodillas, se levantaba y quitaba el tafetán con que estaba cubierto el Cáliz, y el Diácono la Patena. Llegaban a ver el Santísimo Sacramento el Deán o su teniente, el tesorero y el secretario del Cabildo y luego se cubría como estaba, poniéndolo el Obispo en el arca y lo volvía a incensar, concluyendo con el cierre con tres llaves, que tomaba el Obispo, Deán y tesorero, a continuación el secretario del Cabildo ponía su sello encima de cada cerradura. Hecho esto se iba el Obispo y hacía genuflexión en la última grada del Monumento, tomaba la Mitra y se volvía en procesión vía recta al Altar mayor, donde el Obispo y los Ministros en sus asientos ordinarios, esperaban que se dijesen las Vísperas; acto seguido, el Obispo decía la oración y luego se desnudaba y se iba acompañado de todo el Cabildo. A continuación se desnudaba el Altar como ordenaba el Misal. 
Para el Mandato, en siendo la hora, venía el Cabildo a por el Obispo y éste, se iba al Sagrario y allí se vestía con Amito, Alba, Cíngulo, Estola, Pluvial violado y Mitra simple. Los Asistentes y Ministros eran los mismos que para la bendición de las candelas; llevando todos, ornamentos morados, más dos raciones con Albas y Cíngulos que servían para ayudar a los lavatorios, portando para ello, jarros de plata, fuentes y toallas al hombro.

Desde allí iban todos al Cabildo, donde se ponían los canónigos en sus lugares y el Obispo en la silla del medio. Bendecía el incienso, teniendo la naveta el Diácono, y luego pedía la bendición. A continuación, se cantaba el Evangelio y acabado, se quitaba el Obispo la capa, se ceñía una toalla, y lavaba la mano derecha a los Canónigos, hincado de rodillas, y haciendo una Cruz en ella, se la besaba. Lavaba primero al Deán y luego pasaba al coro del Obispo y después al del Deán. Lavadas las manos, decía los versículos y oraciones como en el Misal. Y acabado, iba todo el Cabildo en procesión, con la Cruz delante que llevaba un Capellán, en el mismo orden como salieron del Sagrario, a la nave de los Reyes, donde estaban los trece pobres que había de vestir el Obispo y los que habían comido en su casa, y con las mismas ceremonias y dicho el Evangelio, les lavaba el pie derecho, se lo besaba y les daba limosna el limosnero de parte del Obispo, y de parte del Cabildo, lo hacían dos Canónigos.

Hecho el lavatorio, el Obispo se ponía la capa y decía los versículos y oración y asistía de aquella manera al sermón que se predicaba allí, habiéndose dado la bendición al Predicador antes que se dijese el Evangelio. Acabado el sermón iba el Obispo al Sagrario, y allí se desnudaba, y acompañado de sus Ministros se iba al coro a tinieblas.

\section{EL VIERNES SANTO EN LA REGULACIÓN DEL CEREMONIAL DE 1617.}

Del oficio del Viernes Santo ${ }^{3}$.

Acabada Sexta, iba el Obispo a la iglesia acompañado de los Prebendados, los que se habían de vestir con él, que son los que se vestían para Misa de Pontifical. Llegado al Altar y hecha

\footnotetext{
${ }^{3}$ Capítulo diecinueve. Del oficio del Viernes Santo.
} 
oración se iba a su silla, que estaría sin dosel, y con almohadas al lado de la Epístola, y allí decía en pie el Paternoster y el ave María. Entonces, el coro decía Nona. El Obispo estaba sentado hasta que se acababan los salmos, y cuando se decía Christus factus est, se ponía de rodillas, y decía la oración; y una vez acabada, se retiraba los ornamentos de Misa del Pontifical que estaban puestos sobre el Altar, excepto el calzado y guantes que no se usaban este día, a la vez que no decía los salmos. Vestido hasta la Casulla, Manipulo inclusive y Mitra simple, se ponían el Diácono y Subdiácono los Manipulos junto con los asistentes. Los demás Ministros no se ponían en pluviales sino con sobrepellices. Acabado de vestir iba con Mitra, y Báculo y se hincaba de rodillas delante del Altar, reclinado sobre un genuflexorio que había de estar delante de él y allí hacía oración un buen rato mientras los Ministros ponían la sábana en el Altar.

Levantándose de la oración se volvía a su silla, y sentado en ella, se comenzaba el oficio en el coro, diciendo la profecía un Prebendado, y mientras cantaba el coro el tracto, leía el Obispo la profecía y tracto, y acabado de cantar se levantaba y decía la oración por el libro que estaba sobre el Altar al lado de la Epístola. Después, se volvía a sentar mientras se cantaba la Epístola, y una vez acabada de cantarla leía el tracto.

Una vez que habían comenzado los cantores a cantar la Pasión, se levantaban todos, y el Obispo la leía por el Misal que había de estar en el Altar al lado de la Epístola. Acabada de cantar la pasión se cantaba el Evangelio. El Obispo la oía, vuelto al canónico que lo cantaba, con Báculo, y sin Mitra, y acabado decía las oraciones del Misal, y una vez quitada la Casulla descubría la Cruz en tres veces, primero la cabeza de la cruz, teniendo arrimadas a la paredes las espaldas y el brazo derecho al cuerpo del Altar; luego el brazo derecho y la cabeza del Cristo, arrimado a la parte anterior del Altar en el lado de la Epístola, y por último, en medio del Altar, descubría toda la Cruz con las ceremonias que decía el Misal. Desde allí el Obispo, acompañado de los Diáconos, llevaba la Cruz al lugar a donde se había de adorar, que era una almohada negra cubierta con un paño, y puesta allí se apartaba, se descalzaba y la adoraba sólo, haciendo tres genuflexiones dentro de una distancia competente, que la primera era cerca de la reja del coro y la última junto a la misma Cruz, y ofrecía su limosnero, lo que quería el Obispo, que solía ofrecer 33 reales. Se iba a su silla y se calzaba, donde leía lo que el coro cantaba mientras duraba la adoración de la Cruz que 
hacían los Prebendados de dos en dos, haciendo la misma ceremonia. Primero los asistentes luego los Diáconos, los canónigos de Mitra, Báculo, y libro y Gremial. Luego el Deán y los demás por sus antigüedades.

Podía darse la situación de que se encontrasen dentro de la iglesia, autoridades civiles como eran el Corregidor o los Regidores, en este caso, estos últimos adoraban la Cruz después del coro y acabada la adoración, el Diácono llevaba la Cruz al Altar. El Obispo se lavaba las manos portando Mitra y luego tomaba la Casulla e iba en procesión al Monumento saliendo por la puerta de la capilla mayor, daba la vuelta por detrás del coro hasta la nave donde estaba el Monumento. Llegado el Obispo desde la grada, hacía genuflexión sin Mitra y luego subía al Altar, y hacía oración hincado de rodillas sobre una almohada. Puesto luego de pie, con incienso en dos incensarios y sin bendición, abría el arca el Diácono. El Obispo se ponía de rodillas ante el Santísimo Sacramento, se levantaba y descubría el Cáliz, y sacándole del arca lo ponía sobre el Altar. A continuación, quitaba la patena el Diácono, y teniendo el Cáliz del Obispo en las manos, enseñaba el Santísimo Sacramento a los que entonces le vieron cuando se encerró. Lo volvía a cubrir, y se ponía hincado de rodillas, y lo recibía de mano del mismo Diácono. A continuación, iba la procesión al Altar mayor por la nave de los Racioneros y de la piedad. Una vez llegado el Obispo al Altar, ponía el Santísimo Sacramento en incienso, y hacía las demás ceremonias conforme disponía el Misal, y habiendo consumido se ponía la Mitra y se lavaba las manos e iba a su silla, donde esperaba que se acabasen las Vísperas, decía la oración y acabada, se desnudaba e iba a su casa acompañado de todos los Prebendados.

\section{EL SABADO SANTO EN LA REGULACIÓN DEL CEREMONIAL DE 1617.}

Del oficio del Sábado Santo ${ }^{4}$.

Si el Obispo este día de Sábado Santo quería ir a la Iglesia, debían de ir a por él los seis prebendados a la hora que avisase el obispo que quería ir a la iglesia, y asistía a los oficios. Daba la bendición al Diácono para que este dijese la bendición del cirio, y ponía incienso en

\footnotetext{
${ }^{4}$ Capítulo veinte. Del oficio del Sábado Santo.,
} 
el incensario acompañado de bendición. En la misa, se hacían con él las ceremonias que en las demás misas solemnes, guardando además en lo que había diferencia las rúbricas del misal, haciéndolo al final da la bendición. Le acompañan todos, si quería celebrar todos los oficios o parte de ellos, entonces, se vestía en su silla junto al altar mayor, y si tenía que bendecir los granos del incienso y fuego, se ponía Amito, Alba, Cíngulo, Estola, cruz y pluvial morado y mitra simple, y si no quería hacer lo demás se desnudaba y se iba al coro. Si tenía que hacer todo el oficio, se vestía como se hacía para misas de pontifical, calzado blanco, y lo demás morado, hasta la casulla. Una vez dichas las profecías y oraciones, se quitaba la Túnica y Tunicela, y se ponía pluvial morado para la bendición de la Villa, como en el misal, y una vez hecho esto, volvía con la procesión cantando la letanía al altar mayor, y cuando se decía en la letanía Peccatores, se levantaba y se quitaba en su silla la capa y estola morada y se ponía ornamentos blancos para la misa, mientras en el coro se cantaban los Kyries, y la proseguía como las demás misas de pontifical, guardando en lo particular las reglas del misal. Una vez que había cantado el subdiácono la epístola, besaba la mano al Obispo, el cual sentado leía la Epístola, y una vez acabada, se levantaba y sin mitra cantaba el Aleluya por el libro que tenía el Racionero y que le era presentado por el diácono. A continuación, repetía el coro haciéndolo hasta tres veces subiendo cada una, como en el misal. Volviéndose a sentar proseguía el tracto, el Evangelio y lo demás. Habiendo consumido y lavándose las manos con mitra al cuerno del altar, se sentaba en su silla, y en el coro, se cantaba el Aleluya para vísperas, y una vez repetida después del salmo Laudate Dominum, entonaba el Obispo de pie y sin Mitra la antífona Ad Magnificat, siendo pre entonada por el Subdiácono y el coro la proseguía. Entre tanto, el Obispo sentado y con mitra ponía incienso en el incensario acompañando de su bendición. Comenzando el cántico iba al altar, y lo incensaba como en las demás Vísperas, y una vez hecho esto, se volvía a su silla, donde lo incensaba el Diácono. Mientras se cantaba la antífona se sentaba con Mitra y una vez acabada, iba al altar, decía Dominus Vobiscum y acabada la misa como los demás días se iba a su silla a desnudar, y de allí le acompañaba todo el Cabildo. Si esa tarde quería decir Completas, no se vestía ornamento ninguno para ellas, sino con la capa de coro, en su silla del coro respondía a lube Domine que decía un colegial o mozo de coro, el cual, debía ser graduado y éste, cantaba Frates sobrijestore. El Obispo decía la confesión y absolución, Convertenos Deus y Deus in adiutorium, y comenzado el salmo se sentaba, excepto al Gloria Patri, como se hacía en las 
Vísperas. En el himno estaba de pie y a la Capitula que decía el canónigo semanero, el Obispo decía la oración Visita y la que se dice después de Regina caeli, teniendo el libro un cancionero y se iba a su casa acompañado de todo el coro.

\section{CONCLUSIONES}

A través de este trabajo, descubrimos que el ceremonial religioso se dedica a estudiar la importancia de la praxis litúrgica y la existencia de rituales religiosos. El ceremonial religioso, pretende enseñar y dar a entender sus símbolos, cómo se procede en el funcionamiento de sus actos y la realización de sus ceremonias por ser la principal vía de manifestación y expresión de los métodos e instrucciones que intervienen en sus manifestaciones religiosas.

Dentro del ceremonial religioso, se evidencian muestras de atención y respeto en donde nos muestran los datos historiográficos que enmarcan la práctica del Ceremonial en Cuenca en los actos religiosos realizados en la Catedral de Cuenca. Sin embargo no podemos, negar la evidencia de que son parciales e incompletos, debido a la escasez de los documentos que contienen las normas sobre su desarrollo en la documentación conservada; pero que sin embargo, nos enseñan y nos dan testimonio de la existencia de unas normas sobre actos religiosos, que como se comprueba con el paso del tiempo, los nuevos Ceremoniales, se limitan a recogerlas casi en su totalidad, aunque eso sí, adaptándolas a las transformaciones y exigencias dela Iglesia. Sin embargo no deja de tener interés para el estudio evolutivo del Ceremonial religioso en España. La dificultad reside en la escasa y dispersa información existente; pero de cuyo análisis obtenemos la visión histórico-artística de esta manifestación.

El análisis de los documentos encontrados en la Biblioteca Nacional nos enseña que el contexto era significativamente solemne y respetuoso en la ceremonia eucarística, donde se acumulan gestos de bienvenida y despedida, durante el rito de la exposición de los dones para su ofrenda estos, que son palabra de la ofrecimiento de la Iglesia, son exaltados donde se encuentran a la vez, el celebrante y toda la Asamblea proponente, y se exponen juntos, el 
honor y el respeto por la ofrenda y los que la ofertan. En los actos religiosos de la Semana Santa, toda la Asamblea comparte la gracia de la paz del Señor resucitado.

En la función litúrgica y el orden sagrado que se desarrolla en los actos religiosos de la Semana Santa, se observa al mismo tiempo, la existencia de solemnidad y antigüedad existente entre los miembros que actúan en estas ceremonias. Coexistía por tanto, una perfecta asociación explícita entre los textos y los tiempos litúrgicos, junto a los signos, símbolos y colores, formando un acabado impresionante para todos los que asistían a las transcritas ceremonias. Con ello, logramos el conocimiento detallado de los usos, costumbres, hábitos, prácticas y ceremonias del protocolo religioso. Nos enseña en síntesis, y nos lleva a decretar la naturaleza y el desarrollo del ceremonial religioso que se desenvuelve en la Semana Santa conquense y de sus ritos y símbolos, en definitiva, de sus componentes internos y externos y la gran significación y validez de sus símbolos y actos tanto en la vida religiosa, como en el desarrollo dentro de la participación en estos ceremoniales de la vida civil.

\section{BIBLIOGRAFÍA.}

CALLAHAM, W.J. (2002) La Iglesia católica en España (1875-2002). Barcelona. Editorial Crítica S.L.

CID, C.; RíU, M.; CASTILLO, A. del. (1965) Historia de las Religiones. Editorial Ramón Sopena S.A.

CONTRERAS MAZARÍO, J. M. (2011). Marco jurídico del factor religioso en España. Madrid. Editorial Observatorio del Pluralismo Religioso en España.

DÍAZ BONILLA, M.A. (2003) Organización, ceremonial y protocolo en la Iglesia Católica. Madrid: Ediciones Protocolo.

ESCALERA AICUA, S. (2005). Ceremonial y protocolo religioso. Madrid: Ediciones Protocolo. 
MARTINEZ DE ANTOÑANA, R.P. Gregorio. (1952) Manual de Liturgia Sagrada. Madrid. Editorial del Corazón

MORENO GONZÁLEZ, J.R (2011). Introducción al protocolo eclesiástico. Madrid: CEU Ediciones.

PARDO, A. (1998) Rituales de Los Sacramentos: Textos Litúrgicos Oficiales. Madrid. Biblioteca de autores cristianos.

SÁNCHEZ GONZÁLEZ, D. Del M. (2011). Fundamentos del Ceremonial y del Protocolo. Madrid: Editorial Síntesis.

SÁNCHEZ GONZÁLEZ, D. Del M. (coord.) (2012). Protocolo. Tradiciones, actualidad y crisis. Madrid: Sanz y Torres-UNED. 